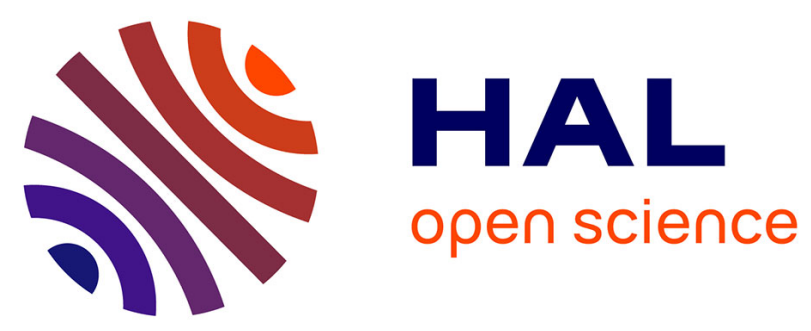

\title{
Diagnostic criteria in Pai syndrome: results of a case series and a literature review
}

Anne Morice, Eva Galliani, Jeanne Amiel, Martin Rachwalski, Cecilia Neiva, C. Thauvin-Robinet, Marie-Paule Vasquez, Arnaud Picard, Natacha Kadlub

\section{- To cite this version:}

Anne Morice, Eva Galliani, Jeanne Amiel, Martin Rachwalski, Cecilia Neiva, et al.. Diagnostic criteria in Pai syndrome: results of a case series and a literature review. International Journal of Oral and Maxillofacial Surgery, 2019, 48 (3), pp.Pages 283-290. hal-01948492

\section{HAL Id: hal-01948492 \\ https://u-bourgogne.hal.science/hal-01948492}

Submitted on 21 Oct 2021

HAL is a multi-disciplinary open access archive for the deposit and dissemination of scientific research documents, whether they are published or not. The documents may come from teaching and research institutions in France or abroad, or from public or private research centers.
L'archive ouverte pluridisciplinaire HAL, est destinée au dépôt et à la diffusion de documents scientifiques de niveau recherche, publiés ou non, émanant des établissements d'enseignement et de recherche français ou étrangers, des laboratoires publics ou privés.

\section{(ㅇ)(1) $\$$}

Distributed under a Creative Commons Attribution - NonCommerciall 4.0 International 


\title{
Diagnostic criteria in Pai syndrome: results of a case series
}

\section{and a literature review}

\author{
Anne Morice ${ }^{1,2}$, Eva Galliani ${ }^{1}$, Jeanne Amiel ${ }^{2,3,4}$, Martin Rachwalski ${ }^{1,4,5}$, Cecilia \\ Neiva $^{1}$, Christel Thauvin-Robinet ${ }^{6}$, Marie-Paule Vazquez ${ }^{1,2}$, Arnaud Picard ${ }^{1,2}$, \\ Natacha Kadlub ${ }^{1,2}$
}

${ }^{1}$ Department of Maxillofacial and Plastic Surgery, Rare Diseases Reference Centre Coordinator for Clefts and Facial Malformations, Hôpital Universitaire NeckerEnfants Malades, Paris, France

${ }^{2}$ Université Paris Descartes-Sorbonne Paris Cité, Paris, France

${ }^{3}$ Department of Medical Genetics, Hôpital Universitaire Necker-Enfants Malades, Paris, France

${ }^{4}$ Imagine Institute of Genetic Diseases, Université Paris Descartes-Sorbonne Paris Cité, Paris, France

${ }^{5}$ Department of Paediatric Neurosurgery, National Reference Centre for Craniofacial Malformations, Hôpital Universitaire Necker-Enfants Malades, Paris, France ${ }^{6}$ Department of Genetic Diseases, Reference Centre for Developmental Anomalies and Malformative Syndromes, Centre Hospitalier Universitaire, Dijon, France 


\begin{abstract}
Pai syndrome was originally described as the association of a midline cleft lip, midline facial polyps, and lipoma of the central nervous system. However, only a few patients present with the full triad, and most exhibit a wide spectrum of phenotypic variability. The aim of this study was to phenotypically delineate Pai syndrome and to propose new criteria to facilitate a clinical diagnosis in the future. The study cohort consisted of seven case patients and an additional 60 cases diagnosed with Pai syndrome identified in a literature review. Only 23 of 67 patients presented the full triad as historically described by Pai et al. (1987). A congenital facial midline skin mass was always encountered, particularly affecting the nasal structures (60/67). A midline facial cleft was reported in 45 of 67 patients and a pericallosal lipoma in 42 of 67 patients. The proposed definition of Pai syndrome is the association of (1) a congenital nasal or mediofrontal skin mass or a mid-anterior alveolar process polyp as a mandatory criterion, and at least one of the following criteria: (2) midline cleft lip and/or midline alveolar cleft, and/or (3) a pericallosal lipoma or interhemispheric lipoma in the case of corpus callosum dysgenesis.
\end{abstract}

Key words: Pai syndrome, midline cleft lip, skin tag, pericallosal lipoma, frontonasal dysplasia

\title{
Introduction
}

Pai syndrome is a rare congenital craniofacial malformation involving the midline cranial and facial structures. According to the literature, Pai syndrome is 
phenotypically highly variable and overlaps with frontonasal dysplasia spectrum in some cases $^{1-3}$. Most of the cases of Pai syndrome described in the literature do not meet all criteria as initially defined by Pai et al., i.e., (1) a midline cleft lip, (2) midline nasal and facial polyps, and (3) lipoma of the central nervous system ${ }^{4}$. Less stringent diagnostic criteria have been proposed, including the presence of at least (1) a midline cleft lip, and (2) one hamartomatous nasal polyp and/or mid-anterior alveolar process polyp $^{5}$, or the association of a congenital nasal polyp and one of the three following criteria: (1) midline cleft lip, (2) mid-anterior alveolar process congenital polyp, or (3) a pericallosal lipoma ${ }^{3}$.

Most cases are sporadic, and although an autosomal dominant inheritance has been suggested, the aetiology remains unknown ${ }^{2,6}$. Establishing homogeneous study cohorts in the future may help to elucidate the aetiology of Pai syndrome. Thus, there is the need for a consensus definition of Pai syndrome.

This article describes a series of seven additional patients diagnosed with Pai syndrome and provides a review of cases reported in the literature according to the three current clinical diagnostic criteria. The aim of this study was first to describe the phenotype spectrum of reported cases of Pai syndrome and to determine whether these cases are consistent with the existing definitions of Pai syndrome. The second aim was to propose more appropriate diagnostic criteria and systematic investigations, based on these findings.

\section{Patients and methods}

\section{Patients}


A retrospective study was conducted in the Rare Diseases Reference Centre for Cleft Lip and Palate and Facial Malformations at Hôpital Trousseau and Hôpital Universitaire Necker-Enfants Malades, Paris, France, covering the years 2008 to 2018. Using the CEMARA database (Banque Nationale de Données Maladies Rares), seven patients diagnosed with Pai syndrome were identified. These patients presented at least two criteria of the triad as defined by Pai et al. ${ }^{4}$, with a midline facial congenital skin mass as a mandatory criterion. The following information was collected from a chart review: sex, birth parameters, location of the congenital facial skin mass, description of the facial cleft and additional abnormalities, neuropsychological development, and results of genetic investigations. Cerebral magnetic resonance imaging (MRI) scans were reviewed to determine the type of pericallosal lipoma and any additional central nervous system malformations.

\section{Literature review}

The review of the literature was conducted by screening the PubMed database using the terms "Pai syndrome" and/or "midline lip cleft" and/or "facial skin mass" and/or “cutaneous polyps" and/or "lipoma of the corpus callosum". This analysis included case reports and series of Pai syndrome, as well as literature reviews published since 1965.

\section{Results}

Case series (Table 1, Figs. 1-3) 


\section{[Table 1 here]}

\section{[Figures 1-3 here]}

Seven patients were included in this study, five female and two male, with a median age of 1 month (range $0.25-5$ months) at initial examination and a median follow-up of 9 years (range $0.5-19$ years). For all patients, family history was unremarkable, and the patient's parents were not consanguineous. Patients 5 and 7 each had a nonaffected dizygotic twin. Cleft lip was diagnosed prenatally in two patients (patients 2 and 7).

Among the seven patients, four presented with the full triad (patients 1-4) as described by Pai et al. ${ }^{4}$, whereas three patients presented two criteria (patients 5-7; Table 1; Fig. 1). A midline nasal skin mass was present in all cases, a midline facial cleft was observed in six of seven cases, and a pericallosal lipoma was seen in five of seven cases (Fig. 3 [Au?1]). Multiple congenital skin tags were present in three of seven patients (Table 1; Fig. 2 [Au?2]).

Ophthalmological abnormalities were diagnosed in two patients, including a hyperpigmented spot of the iris and a limbal dermoid. Intracranial abnormalities were also detected, including partial agenesis of the corpus callosum, short corpus callosum, choroid cyst, and agenesis of the olfactory bulbs. Hypertelorism, bifid nose, and down-slanting palpebral fissures were noted in patient 3 (Fig. 1). Two patients presented a bifid midline frenum of the upper lip (Fig. 2 [Au?2]). Neuropsychological development was considered in the normal range for all patients.

\section{Literature review}


Fifty articles matched the research criteria, including 46 case reports and four case series (from two to seven patients per series). Among these case reports and series, nine included a review of the literature $e^{3,5,7-13}$.

In total, 60 cases of Pai syndrome have been described to date. Nineteen patients met the three clinical criteria as defined by Pai et al. ${ }^{4}$ (Supplementary

Material, Table S1). Thirty-six patients presented two of the three criteria: 14 patients had at least one nasal skin mass and a midline cleft of the upper lip, 15 patients had at least one congenital nasal skin mass and a pericallosal lipoma, and seven patients presented with a paramedian cleft lip or midline alveolar cleft without cleft lip, associated with midline facial polyps and/or a pericallosal lipoma (Supplementary

Material, Table S2). Forty-two cases featured additional abnormalities, with multiple congenital facial skin masses (40/60), hypertelorism (19/60), and ophthalmological anomalies (19/60) being the most frequently observed (see Supplementary Material, Tables S1 and S2). Five patients presented one criterion only (i.e., nasal congenital skin mass).

\section{Discussion}

The phenotypic spectrum of the reported cases of Pai syndrome is heterogeneous ${ }^{2}$, as are the diagnostic criteria ${ }^{3-5}$, which was confirmed by the present review. This study first described the phenotype of seven additional cases of Pai syndrome and then compared them with 60 cases of Pai syndrome reported in the literature to date, in order to determine whether these cases are consistent with the existing definitions of Pai syndrome. The second aim was to critically analyse the three definitions of Pai 
syndrome and, on the basis of the results, to propose new diagnostic criteria as well as systematic investigations.

\section{Analysis of the clinical spectrum of Pai syndrome}

Congenital facial skin masses

Almost all cases reported in the literature, as well as the cases in the series presented herein, harboured a facial midline hamartoma (57/60 cases in the literature and 6/7 cases in this series). Castori et al. have previously noted that this is the most frequently encountered feature ${ }^{5}$. These congenital skin masses affected the nasal structures in 53 of 60 cases reported in the literature, particularly the nostrils, and this was also seen in the present case series. In a few cases, examination of the skin masses revealed a lipoma or a myolipoma ${ }^{14-19}$ or a dermoid cyst $^{6}$, as in two patients in the case series (see Table 1).

\section{Midline cleft lip}

Midline cleft lip is rare and represents $0.43 \%$ to $0.73 \%$ of cases of cleft lip and palate $e^{9,20}$. In the literature, midline clefts were reported in 39 of 60 patients with Pai syndrome (65\% [Au?3]), with a wide range of severity exhibited (Supplementary

$\underline{\text { Material, }}$ Tables S1 and S2). In the case series, six of seven patients had a midline cleft lip, and one patient presented with a paramedian cleft lip, a median notch of the upper lip, and a midline alveolar cleft (see Table 1). In the literature, three patients 
with Pai syndrome presented with uni- or bilateral paramedian lip clefts ${ }^{2,21,22}$. In four cases, a midline alveolar cleft without cleft lip was reported ${ }^{3}$.

\section{Pericallosal lipoma}

Intracranial lipomas represent less than $0.1 \%$ of intracranial anomalies. They are mostly located in the midline 22,23 . Anterior lipomas of the corpus callosum are mostly of tubulonodular type and frequently associated with hypoplasia or agenesis of the corpus callosum, frontal encephalocele, frontal lobe anomalies, and ocular anomalies. Posterior lipomas are typically described as curvilinear; they are thin and typically lie on the splenium. They are rarely associated with corpus callosum and/or encephalic anomalies ${ }^{23,24}$. A pericallosal lipoma or interhemispheric lipoma was identified in 37 of 60 patients with Pai syndrome; however, cerebral imaging was available for only 49 of the 60 patients. In the case series presented, five patients had a corpus callosum lipoma (tubulonodular in four cases and curvilinear type in the other). One patient with a tubulonodular pericallosal lipoma also presented partial agenesis of the corpus callosum.

Intracranial lipomas are rarely symptomatic ${ }^{23}$, and in Pai syndrome, neuropsychological development is usually normal ${ }^{3}$, as confirmed in the case series. However, neuropsychological development is not well studied in Pai syndrome, and several conditions reported in Pai syndrome are likely to cause neuropsychological impairments. These include associated chromosomal abnormalities such as translocation $\mathrm{q} 28 ; \mathrm{q} 11.2^{25}$, intracranial calcifications ${ }^{9,26}$, and corpus callosum dysgenesis $^{9,27}$ or agenesis ${ }^{2,5,19}$. Patients with Pai syndrome with corpus callosum dysgenesis $^{27}$, hypoplasia or agenesis ${ }^{2,19}$, or other cerebral malformations ${ }^{6,28}$ often 
present with an interhemispheric lipoma (Supplementary Material, Table S2). Thus, systematic cerebral imaging is recommended when a congenital midline facial skin mass and/or midline facial cleft is encountered, as there may be associated cerebral malformations ${ }^{6,28}$ [Au?4]. Cerebral imaging studies are imperative, as a pericallosal lipoma may become symptomatic at a later age, with the risk of developing epilepsy, which has been reported to occur in up to $50 \%$ of patients ${ }^{29}$ [Au?4].

\section{Additional features}

The most frequent additional features encountered in the literature review were multiple congenital facial skin masses (66\%), hypertelorism (32\%), and ophthalmological anomalies (32\%). In the case series, three of seven patients presented with multiple congenital facial skin masses. Two patients showed ophthalmological anomalies: a hyperpigmented spot of the iris and an ocular dermoid. The clinical spectrum of ophthalmological anomalies described in the literature is wide (Supplementary Material, Tables S1 and S2). However, Castori et al. suggested that they could be underestimated ${ }^{5}$. Thus, systematic and complete ophthalmological examination is justified when encountering Pai syndrome.

Ear anomalies are rare and these included pre-auricular skin tags and/or ear dysplasia in five of 60 patients $^{21,30}$. In the case series, one patient had three left preauricular skin tags and bilateral, symmetrical external ear dysplasia in addition to an ocular dermoid. The presence of ear dysplasia and epibulbar dermoids raises the possibility that there might be an overlap with Goldenhar/oculo-auriculo-vertebral (OAV) spectrum and oculoauriculofrontonasal syndrome, which is associated with features of both frontonasal dysplasia and OAV spectrum. 


\section{Defining Pai syndrome}

To date, three definitions of Pai syndrome have been described ${ }^{3-5}$. Pai et al. postulated that three criteria, i.e., a midline cleft lip, midline facial and nasal skin polyps, and lipoma of the corpus callosum, must be present ${ }^{4}$, whereas according to Castori et al..$^{5}$ and Lederer et al. $^{3}$, at least two criteria are sufficient: one or more hamartomatous nasal polyp(s) plus a midline facial cleft (midline cleft lip with or without cleft alveolus) and/or mid-anterior alveolar process congenital polyp (Castori et al..$^{5}$ ) or the presence of a congenital nasal polyp plus one of the following three features: midline cleft lip (with or without cleft alveolus), mid-anterior alveolar process congenital polyp, or pericallosal lipoma (Lederer et al. ${ }^{3}$ ).

In all three definitions, a midline congenital skin polyp must be present. According to Pai et al. ${ }^{4}$, the congenital skin polyp may be located not only in the nasal region but also in the midline facial regions, whereas Castori et al. ${ }^{5}$ and Lederer et al. ${ }^{3}$ restricted this to the nasal structure only. Contrary to Lederer et al. ${ }^{3}$, a midline cleft lip must be present to define Pai syndrome in the two other definitions. Pericallosal lipoma is an obligatory criterion according to Pai et al. ${ }^{4}$, a possible associated feature in the definition of Lederer et al. ${ }^{3}$, and excluded from the diagnostic criteria of Castori et al. 5 .

In the literature review, less than a third of the cases [Au?5] (19/60) met the criteria defined by Pai et al. ${ }^{4}, 34$ of 60 cases met the Castori et al. criteria ${ }^{5}$, and 50 of 60 cases corresponded to the definition of Lederer et al. ${ }^{3}$. In the case series of seven patients, four presented the triad as defined by Pai et al. ${ }^{4}$ and six met the criteria described by Castori et al. ${ }^{5}$ and Lederer et al. ${ }^{3}$. Patient 6 did not meet the existing 
definitions, as she presented with a congenital dermoid cyst of the nasal tip and not a hamartomatous polyp, in addition to a pericallosal lipoma without a midline cleft lip. Several cases diagnosed with Pai syndrome reported in the literature did not present with a hamartomatous polyp but rather with a congenital lipoma or a myolipoma ${ }^{14-19}$ or a dermoid cyst ${ }^{6}$. The pathological diagnosis is not described systematically in previous reports; thus, it is possible that the number of cases without a true hamartomatous polyp may have been underestimated [Au?4]. In addition, these congenital skin masses diagnosed as dermoid cysts or lipoma correspond to congenital and non-progressive lesions of developmental origin that may occur in the midline facial structures. In accordance with the existing definitions, it is considered that a midline congenital skin mass should be a mandatory criterion for defining Pai syndrome, as it was present in all of the cases in the literature review, occurring in the frontal and/or nasal regions as in the definition of Pai et al. ${ }^{4}$ In addition, it is proposed that the possible location be broadened to the mid-anterior alveolar process and its possible pathological diagnoses to dermoid cysts and hamartomatous-like lesions, such as lipoma or myolipoma.

In fact, the initial definition of Pai et al. is relatively restrictive. However, although this congenital malformation affecting the craniofacial midline structures can be expressed in various degrees, it can nevertheless be explained by similar pathophysiological processes [Au?4]. From a pathophysiological point of view, two theories may explain the occurrence of a median cleft of the upper lip: the 'fusion theory' and Veau's theory of mesodermal penetration. According to the fusion theory, the cleft of the upper lip is due to a lack of fusion of the maxillary processes with the frontonasal process during foetal face development ${ }^{31}$. In Veau's theory, the median cleft of the upper lip results from abnormal mesenchymal penetration in the epithelial 
wall of the primary palate during the sixth week of gestation ${ }^{32}$. This second mesodermal theory may also explain the presence of congenital skin masses associated with a median cleft of the upper lip, as a result of compensatory proliferation of mesodermal tissues, where the fusion of the facial processes occurs at the same embryonic stage $\mathrm{e}^{33}$, as well as the occurrence of pericallosal lipoma, as a result of mesodermal inclusion within the closing neural tube ${ }^{34}$ [Au?4]. Several additional pathophysiological processes seem to be responsible for the development of pericallosal lipoma, including the persistence and abnormal differentiation of primitive meninx, which is a mesenchymal derivative of neural crests, into mature adipose tissue ${ }^{35}$.

Thus, based on the literature review, a new definition for Pai syndrome spectrum is proposed: (1) a congenital nasal or mediofrontal skin mass or [Au?6] a mid-anterior alveolar process polyp (regardless of the pathological diagnosis, i.e., hamartoma, dermoid cyst, or lipoma) as an obligatory criterion, and at least one of the following criteria: (2) midline cleft of the upper lip and/or midline alveolar cleft, and/or (3) a pericallosal lipoma or [Au?6] interhemispheric lipoma in the case of corpus callosum dysgenesis (Fig. 4). Of the 60 cases described in the literature, 55 meet these proposed diagnostic criteria. The remaining five patients presented with only one criterion; however, an MRI was not performed in two of these patients [Au? 4 .

[Figure 4 here]

Perspectives: establishing differential diagnoses and elucidating the aetiology of Pai syndrome 
The molecular basis of Pai syndrome remains unknown. To date, only one de novo reciprocal translocation, $46, \mathrm{X}, \mathrm{t}(\mathrm{X} ; 16)(\mathrm{q} 28 ; \mathrm{q} 11.2)$, has been reported in a case of Pai syndrome including a midline cleft of the upper lip, pedunculated skin masses of the nasal septum, frontal bossing, hypertelorism, short and down-slanting palpebral fissures, short stature, and mental retardation ${ }^{25}$. This phenotype overlaps with frontonasal dysplasia, as observed in $32 \%$ of the cases of Pai syndrome described in the literature review and in one patient in the case series. In patients presenting with Pai syndrome and additional features, chromosomal abnormalities may be detected more frequently, especially when the phenotype overlaps with those observed in frontonasal dysplasia spectrum ${ }^{36}$ or in Goldenhar/OAV spectrum and oculoauriculofrontonasal syndrome, which is associated with features of both frontonasal dysplasia and OAV spectrum. Establishing consensus diagnostic criteria for Pai syndrome and performing systematic genetic investigations, including clinical evaluation by a geneticist and comparative genomic hybridization array, are necessary to better delineate Pai syndrome spectrum and thus shed light on its molecular basis.

\section{Conclusions}

Through the analysis of the case series patients and a literature review, this study was able to further analyse the phenotype of Pai syndrome, leading to the proposed new diagnostic criteria, i.e., (1) a congenital nasal or mediofrontal skin mass or [Au?6] a mid-anterior alveolar process polyp (regardless of the pathological diagnosis, i.e., hamartoma, dermoid cyst, or lipoma) as an obligatory criterion, and at least one of the following criteria: (2) midline cleft of the upper lip and/or midline alveolar cleft, 
and/or (3) a pericallosal lipoma or [Au?6] interhemispheric lipoma in the case of corpus callosum dysgenesis.

Systematic cerebral imaging is recommended in the event that midline facial skin masses and/or a midline cleft lip is encountered, as well as ophthalmological assessment and evaluation by a geneticist to detect additional abnormalities and to establish the differential diagnosis of Pai syndrome or overlapping syndromes [Au?4]. This may help to better delineate the spectrum of Pai syndrome and elucidate its aetiology.

\section{Funding}

No funding was secured for this study.

\section{Competing interests}

All authors have no conflict of interest to declare.

\section{Ethical approval}

As a retrospective case series study, ethics committee approval was not required by the study institution [Au?4].

\section{Patient consent}

Informed consent was collected from the patients' parents for the publication of the photographs prior to submission. 


\section{References}

1. Wu E, Vargevik K, Slavotinek AM. Subtypes of frontonasal dysplasia are useful in determining clinical prognosis. Am J Med Genet A 2007: 143A: 3069-3078. doi: 10.1002/ajmg.a.31963

2. Guion-Almeida ML, Mellado C, Beltrán C, Richieri-Costa A. Pai syndrome: report of seven South American patients. Am J Med Genet A 2007: 143A: 32733279. doi: 10.1002/ajmg.a.31962

3. Lederer D, Wilson B, Lefesvre P, Poorten VV, Kirkham N, Mitra D, VerellenDumoulin C, Devriendt K. Atypical findings in three patients with Pai syndrome and literature review. Am J Med Genet A 2012: 158A: 2899-2904. doi:

10.1002/ajmg.a.35592

4. Pai GS, Levkoff AH, Leithiser RE, Reynolds JF. Median cleft of the upper lip associated with lipomas of the central nervous system and cutaneous polyps. Am J Med Genet 1987: 26: 921-924. doi: 10.1002/ajmg.1320260421

5. Castori M, Rinaldi R, Bianchi A, Caponetti A, Assumma M, Grammatico P. Pai syndrome: first patient with agenesis of the corpus callosum and literature review. Birth Defects Res A Clin Mol Teratol 2007: 79: 673-679. doi: 10.1002/bdra.20392 6. Lees MM, Connelly F, Kangesu L, Sommerlad B, Barnicoat A. Midline cleft lip and nasal dermoids over five generations: a distinct entity or autosomal dominant

Pai syndrome? Clin Dysmorphol 2006: 15: 155-159. doi:

10.1097/01.mcd.0000204987.61990.f0

7. Vaccarella F, Pini Prato A, Fasciolo A, Pisano M, Carlini C, Seymandi PL. Phenotypic variability of Pai syndrome: report of two patients and review of the 
literature. Int J Oral Maxillofac Surg 2008: 37: 1059-1064. doi:

10.1016/j.ijom.2008.06.007

8. Mishima K, Mori Y, Minami K, Sakuda M, Sugahara T. A case of Pai syndrome. Plast Reconstr Surg 1999: 103: 166-170. doi: 10.1097/00006534199901000-00026

9. Szeto C, Tewfik TL, Jewer D, Rideout A. Pai syndrome (median cleft palate, cutaneous nasal polyp, and midline lipoma of the corpus callosum): a case report and literature review. Int J Pediatr Otorhinolaryngol 2005: 69: 1247-1252. doi:

10.1016/j.ijporl.2005.01.038

10. Imai Y, Seino H, Toriyabe S, Tachi M, Yamada A. Cases of true and false median cleft with polypoid masses in the facial midline. Cleft Palate Craniofac J 2007: 44: 667-672. doi: 10.1597/06-120.1

11. Huckstadt V, Heis Mendoza ME, Moresco A, Obregon MG. [Pai syndrome: two new cases with unusual manifestations]. Arch Argent Pediatr 2018: 116: e336e340. doi: 10.5546/aap.2018.e336

12. Melloni-Magnelli LF, de la Garza-Giacomán R, Martínez-Leija H, GuzmánRodríguez R. Primer caso clínico de Síndrome de Pai en México. Cirugía Plástica Ibero-Latinoamericana 2015: 41: 183-189. doi: 10.4321/S0376-78922015000200010 13. Li E, Galvin JA. Ophthalmic abnormalities of Pai syndrome: a case report and review of literature. Ophthalmic Genet 2017: 14: 1-4. doi:

$10.1080 / 13816810.2017 .1381979$

14. Iregbulem LM. Midline clefts of the upper lip. Br J Plast Surg 1978: 31: 6365. doi: 10.1016/0007-1226(78)90018-8

15. Preece JM, Kearns DB, Wickersham JK, Grace AR, Bailey CM. Nasal lipoma. J Laryngol Otol 2007: 102: 1044-1046. doi: 10.1017/S0022215100107224 
16. Morgan DW, Evans JN. Developmental nasal anomalies. J Laryngol Otol 2007: 104: 394-403. doi: 10.1017/S0022215100158542

17. Hollis LJ, Bailey CM, Albert DM, Hosni A. Nasal lipomas presenting as part of a syndromic diagnosis. J Laryngol Otol 2007: 110: 269-271. doi:

$10.1017 / \mathrm{S} 0022215100133389$

18. Patil SB, Harsh S. Lipoma of columella with septal extension in Pai syndrome: report of a rare case. BMC Ear Nose Throat Disord 2017: 17: 657. doi:

10.1186/s12901-017-0035-y

19. AbdollahiFakhim S, Bayazian G, Notash R. Nasal septal lipoma in a child: Pai syndrome or not? Int J Pediatr Otorhinolaryngol 2014: 78: 697-700. doi:

10.1016/j.ijporl.2014.01.027

20. Savasta S, Chiapedi S, Perrini S, Tognato E, Corsano L, Chiara A. Pai syndrome: a further report of a case with bifid nose, lipoma, and agenesis of the corpus callosum. Child Nerv Syst 2008: 24: 773-776. doi: 10.1007/s00381-008-06139

21. Abdelmaaboud M, Nimeri N. Pai syndrome: first reported case in Qatar and review of literature of previously published cases. BMJ Case Rep 2012: 2012: bcr0220125940-0. doi: 10.1136/bcr-02-2012-5940

22. Chousta A, Ville D, James I, Foray P, Bisch C, Depardon P, Rudigoz RC, Guibaud L. Pericallosal lipoma associated with Pai syndrome: prenatal imaging findings. Ultrasound Obstet Gynecol 2008: 32: 708-710. doi: 10.1002/uog.6150 23. Yildiz H, Hakyemez B, Koroglu M, Yesildag A, Baykal B. Intracranial lipomas: importance of localization. Neuroradiology 2005: 48: 1-7. doi:

$10.1007 / \mathrm{s} 00234-005-0001-\mathrm{z}$ 
24. Truwit CL, Barkovich AJ. Pathogenesis of intracranial lipoma: an MR study in 42 patients. Am J Roentgenol 1990: 155: 855-864. doi: 10.2214/ajr.155.4.2119122

25. Masuno M, Imaizumi K, Fukushima Y, Tanaka Y, Ishii T, Nakamura M, Kuroki Y. Median cleft of upper lip and pedunculated skin masses associated with de novo reciprocal translocation 46,X,t(X;16)(q28;q11.2). J Med Genet 1997: 34: 952-954. doi: 10.1136/jmg.34.11.952

26. Guion-Almeida ML, Richieri-Costa A, Saavedra D, Cohen MM Jr. Frontonasal dysplasia: analysis of 21 cases and literature review. Int J Oral Maxillofac Surg 1996: 25: 91-97. doi: 10.1016/S0901-5027(96)80048-8

27. Azurdia J, Burke L, Laub DJ. Pai syndrome: median cleft lip, corpus callosum lipoma, and fibroepithelial skin tag. Eplasty 2014: 14: ic7. eCollection 2014. 28. Guion-Almeida ML, Richieri-Costa A. Frontonasal dysplasia, severe neuropsychological delay, and midline central nervous system anomalies: report of 10 Brazilian male patients. Am J Med Genet A 2009: 149A: 1006-1011. doi: 10.1002/ajmg.a.32717

29. Kieslich M, Ehlers S, Bollinger M, Jacobi G. Midline developmental anomalies with lipomas in the corpus callosum region. J Child Neurol 2016: 15: 8589. doi: $10.1177 / 088307380001500205$

30. Ocak Z, Yazicioglu HF, Aygun M, Ilter MK, Ozlu T. Prenatal detection of Pai syndrome without cleft lip and palate: a case report. Genet Couns 2013: 24: 1-5.

31. Stark RB. The pathogenesis of harelip and cleft palate. Plast Reconstr Surg 1954: 13: 20-39. doi: 10.1097/00006534-195401000-00003

32. Veau V. Bec-de-lièvre. Paris: Masson, 1938. 
33. Nakamura J, Tomonari H, Goto S. True median cleft of the upper lip associated with three pedunculated club- shaped skin masses. Plast Reconstr Surg 1985: 75: 727-731. doi: 10.1097/00006534-198505000-00022

34. Wilberger JE Jr, Maroon JC, Prostko ER, Baghai P, Beckman I, Deeb Z. Magnetic resonance imaging and intraoperative neurosonography in syringomyelia. Neurosurgery 1987: 20: 599-605. doi: 10.1097/00006123-198704000-00016 35. Truwit CL, Barkovich AJ. Pathogenesis of intracranial lipoma: an MR study in 42 patients. Am J Roentgenol 1990: 155: 855-864. doi: 10.2214/ajr.155.4.2119122 36. Ribeiro-Bicudo LA, Quiezi RG, Guion-Almeida ML, Legnaro C, RichieriCosta A. Exclusion of mutations in TGIF, ALX3, and ALX4 genes in patients with the syndrome of frontonasal dysgenesis, callosal agenesis, basal encephalocele, and eye anomalies. Am J Med Genet A 2012: 158A: 1233-1235. doi:

10.1002/ajmg.a.35305 


\section{Figure captions}

Fig. 1. Frontal views of the patients in this series. (A) Patient 1 at the age of 1 year, showing the midline cleft lip and polypoid mass attached to the right side of the nasal septum. (B) Patient 2 at the age of 8 days, showing a large midline cleft lip and a pedunculated skin mass attached to the columella. (C) Patient 3 at the age of 5 months, showing a midline cleft lip, a bifid nose, hypertelorism, wide forehead, downslanting palpebral fissures, and a pedunculated skin mass attached to the right nostril. (D) Patient 5 at the age of 1 month, showing a midline cleft lip, a skin mass of the alveolar cleft arising in the midline lip cleft, and a pedunculated skin mass of the right nostril (pedicled on the nasal septum). (E) Patient 6 at the age of 1 month, showing a midline cleft lip, a skin mass of the alveolar cleft arising in the midline lip cleft, and a pedunculated skin mass of the right nostril (pedicled on the nasal septum) [Au?7]. (F) Patient 7 at the age of 1 month, showing a right paramedian cleft lip, a median notch, and a pedunculated skin mass of the cleft lip, with extension into the right nostril. Note: Informed consent for publication of the frontal photograph was not obtained for patient 4.

Fig. 2. Additional facial features in patients 1, 2, and 4. (A) Intraoral view of patient 1: bifid labial frenum of the maxilla and midline alveolar cleft. (B) Lateral view of patient 2 at the age of 8 days, showing pre-auricular skin tags. (C) Frontal view of patient 4 at the age of 1 month, depicting a pedunculated skin mass attached to the nasal tip and a bifid frenum. 
Fig. 3. Cerebral MRI depicting two types of pericallosal lipoma (sagittal plane): (A) tubulonodular-type lipoma of the corpus callosum (patient 1); (B) curvilinear-type lipoma of the corpus callosum (patient 4).

Fig. 4. Flowchart of new diagnostic criteria for Pai syndrome and suggested investigations. [Au?8] 


\section{A. Patient 1 \\ B. Patient 2 \\ C. Patient 3}

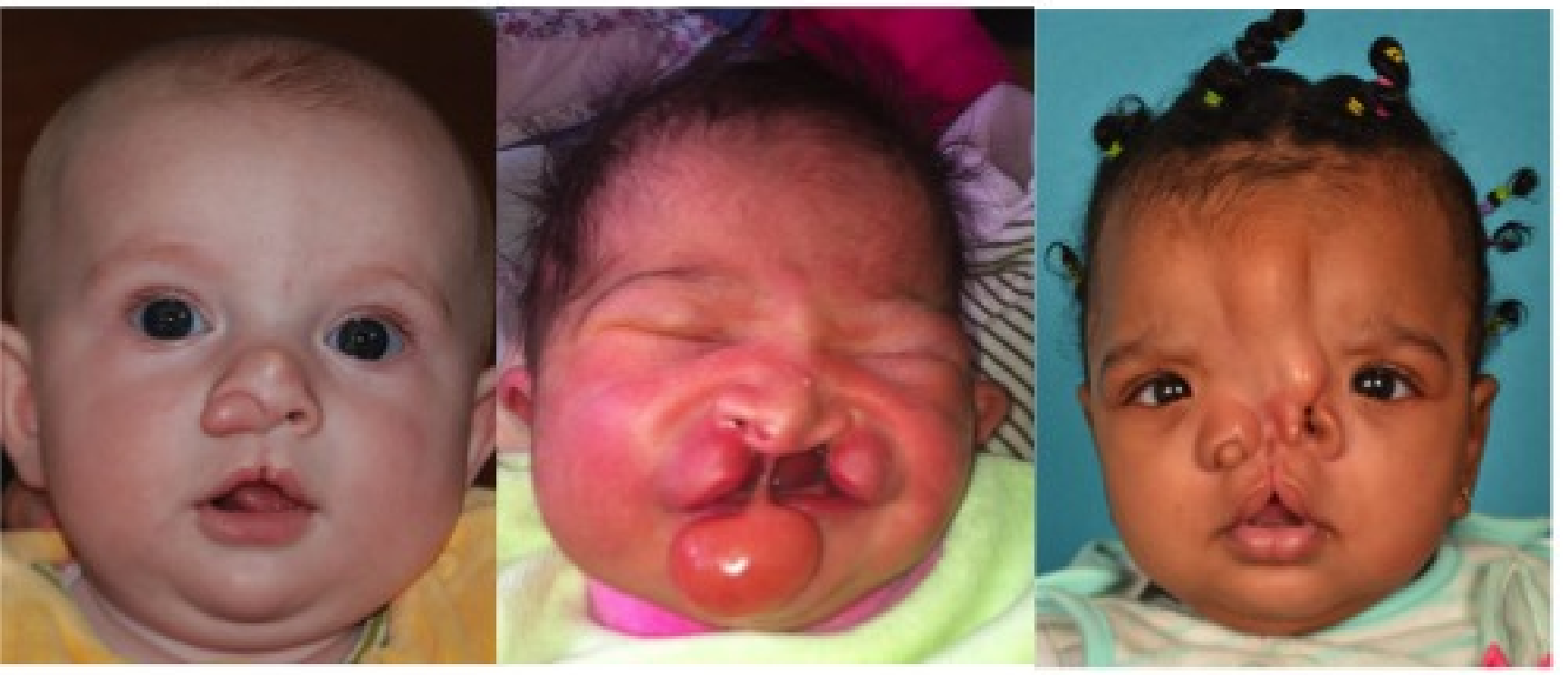

D. Patient 5

E. Patient 6

F. Patient 7 
A. Patient 1

C. Patient 4 


\section{A. Patient 1}

B. Patient 4

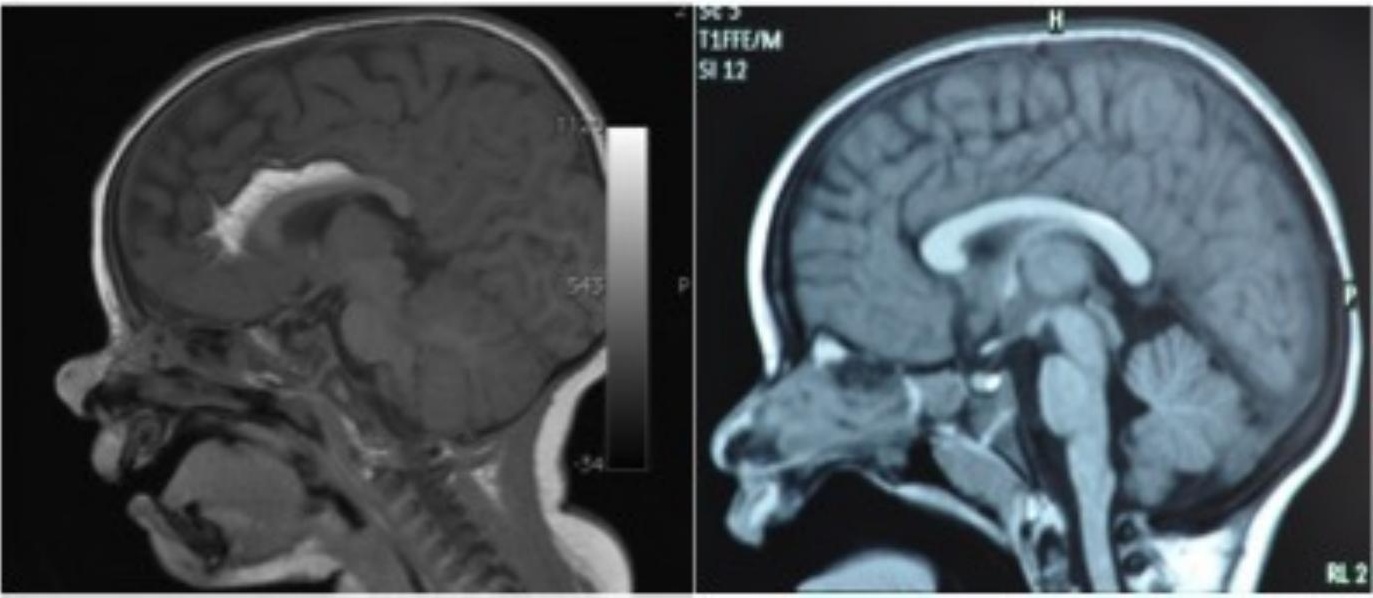


A. $>=1$ congenital nasal or mediofrontal and/or midanterior alveolar process skin mass

AND

B. Median cleft of the upper lip and/or median alveolar cleft

\section{AND/OR}

C. Pericallosal lipoma and/or interhemispheric lipoma in case of corpus callosum dysgenesis

Systematic cerebral imaging in case of A or B or A + B

$\downarrow$

Positive diagnosis of « Pai syndrome » if $\mathrm{A}+\mathrm{B}, \mathrm{A}+\mathrm{C}$, or $\mathrm{A}+\mathrm{B}+\mathrm{C}$

$\downarrow$

Detailed physical examination including complete ophthalmological screening

«Isolated » Pai syndrome if no other abnormalities*
« Associated » Pai syndrome in case of additional unrecognazible or recognizable syndrome
Differential diagnoses

* The definition of additional abnormalities exclude additional congenital facial skin masses of the midline structure 
Table 1. Clinical, radiological, and pathological characteristics of the patients diagnosed with Pai syndrome included in the current series.

\begin{tabular}{|c|c|c|c|c|c|c|}
\hline $\begin{array}{l}\text { Patient } \\
\text { Birth term (weeks) }\end{array}$ & Sex & $\begin{array}{l}\text { Cutaneous facial polyps } \\
\text { (localization, number, and }\end{array}$ & Orofacial cleft & Pericallosal lipoma & Additional findings & $\begin{array}{l}\text { Genetic } \\
\text { investigations }\end{array}$ \\
\hline Birth weight $(\mathrm{g})$ & & histopathological diagnosis) & & & & \\
\hline \multicolumn{7}{|l|}{ Birth height $(\mathrm{cm})$} \\
\hline Patient 1 & Female & Polypoid mass attached to the & Midline cleft of the & Tubulonodular & Bifid frenum of the upper & Not performed \\
\hline 37 weeks +5 days & & right nasal septum (1) & upper lipa & pericallosal lipoma & lip & \\
\hline $3070 \mathrm{~g}$ & & (hamartoma) & (microform) & & & \\
\hline $48.5 \mathrm{~cm}$ & & Nasal skin lesion of the nasal tip & Median alveolar & & & \\
\hline (Figs. 1-3 ) & & (1) (dermoid cyst) & cleft of premaxilla & & & \\
\hline Patient 2 & Female & Diverticula of the nasal dorsum & Complete midline & Tubulonodular & Bilateral ear deformities & $46 \mathrm{XX}$ \\
\hline 40 weeks & & (1) (hamartoma) & cleft lip and palate & pericallosal lipoma & Agenesis of the olfactive & Comparative \\
\hline $2640 \mathrm{~g}$ & & Pedunculated skin mass pedicled & & Short corpus & [Au?10] bulb & genomic \\
\hline $47.5 \mathrm{~cm}$ & & on columella (1) (hamartoma) & & callosum & Left ocular dermoid & hybridization array: \\
\hline (Figs. 1, 2) & & Diverticula of the upper gingiva & & & & normal \\
\hline & & (1) (hamartoma) & & & & (holoprosencephaly \\
\hline
\end{tabular}


pedunculated [Au?9] masses

(one fibrochondroma and two

lipofibromas)

\section{Patient 3}

38 weeks

$2850 \mathrm{~g}$

$48 \mathrm{~cm}$

(Fig. 1)

\section{Patient 4}

41 weeks +5 days

$2980 \mathrm{~g}$

$49 \mathrm{~cm}$

(Figs. 2, 3)
Female Pedunculated skin mass on the nasal tip (1) (hamartoma)
Female cleft of the upper lip

pericallosal lipoma

Partial agenesis of

the corpus

callosum

Midline cleft of the

upper lip

(microform)

Median alveolar

cleft of premaxilla

Curvilinear lipoma
Hypertelorism

Not performed

Bifid nose

Median fistula

(columella)

Down-slanting palpebral

fissures

of corpus callosum lip

High arched palate

Small left choroid plexus

cyst

Hyperpigmented spot in 
the left iris

\begin{tabular}{|c|c|c|c|c|c|c|}
\hline Patient 5 & Male & Pedunculated skin mass of the & Incomplete midline & None & None & Not performed \\
\hline 38 weeks & & right nostril (pedicled on the & cleft of the upper lip & & & \\
\hline $2950 \mathrm{~g}$ & & nasal septum) (1) (hamartoma) & and alveolus & & & \\
\hline $48 \mathrm{~cm}$ & & Skin mass of the alveolar cleft & & & & \\
\hline (Fig. 1) & & $\begin{array}{l}\text { arising in the midline cleft lip } \\
\text { (hamartoma) (1) }\end{array}$ & & & & \\
\hline Patient 6 & Female & Nasal skin mass (columella & None & Tubulonodular & None & Exome sequencing: \\
\hline 40 weeks & & extending to the right alar dome) & & pericallosal lipoma & & no abnormalities \\
\hline $2950 \mathrm{~g}$ & & (dermoid cyst) (1) & & & & \\
\hline \multicolumn{7}{|l|}{$48 \mathrm{~cm}$} \\
\hline \multicolumn{7}{|l|}{ (Fig. 1) } \\
\hline Patient 7 & Male & Pedunculated skin mass of the & Complete & None & Congenital stenosis of & Exome sequencing: \\
\hline 38 weeks & & cleft lip, with extension into the & paramedian cleft lip & & the right lacrimal duct & no abnormalities \\
\hline $2800 \mathrm{~g}$ & & right nostril (1) (hamartoma) & and palate (right & & Duplication of the & \\
\hline $48 \mathrm{~cm}$ & & & side) & & vomerian [Au?11] bone & \\
\hline
\end{tabular}


(Fig. 1)

Midline alveolar

cleft

${ }^{a}$ Characterized by disrupted vermilion-cutaneous junction, hypoplastic mucosal free margin, and notching of the vermilion. 